\title{
The Pedagogy of Learning and Unlearning Empathy
}

\author{
Kenneth J. Shapiro \\ Psychologists for the Ethical Treatment of Animals
}

Eliot empathizes with E.T. almost immediately and despite his fear. His older brother is skeptical, his younger sister is scared, while his mother's first priority is protecting her own. Of course, by the end they all empathize with this strange little creature who walks like a loon, flies like a swan, heals like a god, and misses home like you and me. Even one member of the scientific community empathizes with or feels into E.T.--this despite the presentation of scientists as an elite corps whose high tech instrumentation distances them from their subject.

Why do some people empathize so immediately, so confidently, and so faithfully with this nonhuman animal, while others remain outside of and insensitive to his feelings, intentions, and world? How do we learn empathy, or do we have to learn it? Why are we empathic to some beings and not to others?

First, what is empathy? We all know but we also often confuse it with its neighbors, some of whom on closer examination are quite different. Empathy is a way of understanding another being, particularly understanding his or her feelings, motives, and interests as they are experienced by that being. It is most readily distinguished from objective understanding, as in traditional scientific study, in which we try to stay outside those experiences and outside our own personal experience as well. There are, then, empathic and objective forms of understanding. Both have their own merits and shortcomings. Another distinction - empathy is not feeling sorry for somebody's plight, although sometimes it can lead to it. The latter, sympathy, is already a judgment; empathy is just understanding. It is not yet making a judgment or trying to alleviate a condition. Finally, and the hardest distinction, empathy is not putting yourself in somebody else's shoes to see what it would be like for you. Empathy is less selfish and less vicarious, for it is more directly seeing what it is like being the other person. Empathy is a form of understanding that requires trust and intimacy, for to be empathic we must partly leave ourself behind and, if only for a moment and if only imperfectly, go into the other person's experience. 
How do we first learn empathy? Contrary to what one might think, we do not start somehow inside our own world and slowly learn to find our way out and into somebody else's - and so learn empathy. An infant cries when other infants cry. He or she is anxious when the caretaker is anxious and euphoric when the caretaker is euphoric. Almost from the beginning of life we are out there with others, out there in the one common world, even before we can distinguish between ourself and other selves. We catch the emotional atmosphere by a kind of contagion.

Later, the child gains a clearer sense of self as distinguished from others. The earlier automatic participation is now more selective and active but is still on the level of feelings and bodily posture. The child now actively imitates the behavior of other children and also of animals and even of inanimate objects. As adults, we retain this immediate bodily involvement in the world in the way we open our mouth as we feed the baby, help the pole-vaulter over the bar, and use body English to guide the ball after we hit it.

While not yet quite empathy, both emotional contagion and bodily imitation are the early basis for it. Building on them, the child soon learns to imitate or adopt another person's perspective as well as mood and behavior. For example, Piaget (Flavell, 1963) shows how children in the later grade school years can draw a picture of three papier-mâché mountains as they would appear to a doll sitting in different positions opposite the mountains. By this time the child has the capacity to be genuinely empathic, for he or she can understand the world from another point of view.

However, the child does not stay there. Taking the mountain example again, we learn not only to bracket our own point of view but also those of others so that we can see the mountains from everywhere, from all possible points of view; or, as has recently been described, we learn to appreciate the "view from nowhere." This more formal and abstract understanding allows us to get some distance from any one perspective. However, it also requires us for that moment to stop participating, to stop feeling into the experience of another being. We move from being experience-near to being experience-distant in regard to others and even in regard to our selves. For some of us this objective form of understanding becomes so dominant as to largely exclude the possibility of empathy.

In an earlier stage, the child imputes feelings and motives to almost anything that moves. The sun itself is alive and moves across the highway of the sky to bed down at the end of its long 
journey. As we have just described, the child learns and, to an extent, unlearns empathy. He or she also learns those classes of objects with which it is socially acceptable to empathize. There is the sun on the one hand and cousin Bill on the other. But what of nonhuman animals? Are they included in that class of beings in whose world we participate in the intimate mode of empathy?

Our contemporary society teaches a complex, changing, and really grossly confusing set of lessons regarding what animals are and how we are to relate to them-the "social construction" of animals. The sheer number and variety of classes of socially constructed animals almost matches the seemingly infinite variety of nature itself: the sphinx and the unicorn, Bambi and Donald Duck, Jonathan Livingstone Seagull and Puff the Magic Dragon, the big, bad wolf and the werewolf, Brer Rabbit and Yogi Bear or Smokey the Bear or teddy bear, Fido and the cigarette smoking beagles, cellophane-wrapped boneless chicken, a mink coat, a geep (a genetically engineered sheep/goat cross), the Baltimore Orioles.

We have animaled the world with nonanimal animals and animal nonanimals; with humanoid animals and bestial humans; with machines that become animals and animals that become machines; with fabled, confabulated, and mythopoetic animals; with anonymous swarms and individually named animals; with extinct and genetically spliced together animals; with companion, farm, factory farm, pestilential, and wild animals; with harvested, experimented on, worn, and cooked animals. In this socially constructed reality, animals are so dominant and omnipresent that one anthropologically-minded naturalist, Shepard (1965), argues that they are the first categories a child learns. Or, rather, that a child learns to categorize by categorizing animals, to think by "thinking animals." Indeed, a study of "stories children tell" shows that from the earliest age at which they have narrative competence, even contemporary city-dwelling children tell stories the predominant heroes and villains of which are animals.

Among the lessons society teaches the child is which of these beings are fitting and, really, possible objects of his or her empathic understanding. Those lessons are quite complex and often subtle. Here we can only characterize a few of these socially constructed classes of animals. The primary point is that children are taught to believe that they cannot empathize with animals in some of these classes because they do not have a world, because, in Regan's (1983) term, they are not "subjects of a life." 
Many current practices involving certain classes of animals are so grossly harmful, painful, and exploitive that we could not tolerate them unless we learned to suppress our empathic posture toward those animals. As Serpell (1986) describes, society has built a screen between us and them. The screen consists of various distancing devices: misrepresenting by diminishing their capacities or vilifying them; minimizing contact with them and concealing their suffering; or, oppositely, desensitizing us to their plight by overexposing us to it; multiplying their numbers to the point that we cannot relate to them individually.

In constructing the account of reality that our children and to a large extent we adults learn, the story is told in reverse. Rather than beginning with the practices which shape and form or deform these animals in the first place, and the powerful economic vested interests maintaining them, the story begins with an account of certain animals with whom we are told we need not (because we cannot) empathize. We cannot empathize with them, the story goes, because they are not individuals with their own points of view; they have no world for us to enter.

For example, we teach and are taught that the battery-reared hen is not an individual living a life we could understand, but is rather a commodity, an entity on the commodity exchange market. But clearly, it is only the incredibly intensive husbandry practices that allow us to believe that. By the late grade school years, ironically at the time when a mature empathy becomes possible, the child is taught this story which asserts the impossibility of empathizing with that class of animals he or she eats. This construction replaces the more ambivalent, "This little piggy went to market, this little piggy stayed home, this little piggy ate roast beef."

A second class of animals toward which we teach children to suppress their empathic response are those used in education and in laboratory science. Beginning as early as the grade school years, we require children to dissect an animal. The practices of dissection, vivisection, and invasive experimentation on animals socially construct a class of animals presumed to exist to provide us with educational and scientific tools. These animals are a means to an end, not an end in themselves.

More subtly, dissection teaches that to understand these animals we must cut them up into parts. We cannot know them by empathizing with their behavior and posture, communication and gesture. In addition to helping to construct this particular class of animals, then, this practice teaches a lesson about understanding itself which contributes to the unlearning of 
empathy more generally. Through it, the intimate move of understanding by empathy is further suppressed and replaced by a part-making and part-learning form of understanding. When applied to an animal it deindividuates that animal and degrades animal life in general.

Eliot's frog liberation in E.T. shows the strength of our resistance to the construction of this class of beings who are to be used as our tool and are to be known through cutting them up, as does the growing number of students demanding an alternative to dissection. Interestingly, there is also resistance or at least ambivalence to these practices in biomedical science laboratories. Arluke (1988) has shown that despite elaborate distancing devices to suppress empathy toward laboratory animals, an underlife develops in the subculture of laboratory workers which fosters relating to the animals as both objects and pets, that is, as individuals and possible companions.

Of course, the pet is the clearest example of that socially constructed class of animals with whom the child is taught he or she can empathize. A pet dog or cat is typically viewed as a member of the family, often as the darling of the family. Of course, some of our attempts at empathy with our pet are distortions through which we anthropomorphize his or her world. Still, by and large we are taught to understand and relate to our pet through empathy. As a result we come to understand, for example, how my dog Sabaka spends much of his time seeking and utilizing his own space, places in which he can be relatively secure and from which he can watch for intruders and for opportunities to be closer to us. By comparison, we are taught to know and relate to members of classes of animals clearly akin to Sabaka, a wolf, a coyote, and a dog in the "doglab," only at a distance-and through a veil of fear, vilification, and/or indifference.

What is the significance of empathy in regard to our treatment of animals? To be empathic is not the same as being good or ethical or humane. It does not promise any of those. We typically empathize with our pet, yet as a society our treatment of that class of animals is mixed at best. Like any other form of understanding, empathy can be used in the service of exploitation as well as welfare.

But while it does not promise ethical treatment, empathy can be the basis of an ethic of respect and compassion. Empathy gives us the most direct access we can have to the life of another individual. When we attempt to empathize and are careful to sidestep society's distancing devices and self-protecting con- 
structions, we discover that we can understand directly and accurately even those animals most different from and least dear to us.

Empathy is also important for two other reasons. Psychological studies show that, as compared with external observation, empathy more often leads to more altruistic and less aggressive behavior. Secondly, empathy can be learned or relearned. A major part of the curriculum in counseling and therapy training programs is to learn to help other people through empathy. Empathy can be taught as a set of skills such as attending, listening, and reflecting feelings.

The task of the animal rights movement is to convince society that we can empathize with all animals, and that through empathy we can appreciate their individual and collective plight, and help them.

\section{Notes}

1. For reprints and a list of references consulted in the preparation of this article, write the author, P.O. Box 87, New Gloucester, ME 04260, USA.

\section{References}

Arluke, A. (1988). Sacrificial symbolism in animal experimentation: Object or pet? Anthrozoös, 2(2), 98-118.

Flavell, J. (1963). The developmental psychology of Jean Piaget. Princeton, NJ: Van Nostrand.

Regan, T. (1983). The case for animal rights. Berkeley: University of California.

Serpell, J. (1986). In the company of animals. New York: Blackwell. Shepard, P. (1965). Thinking animals. New York: Viking. 